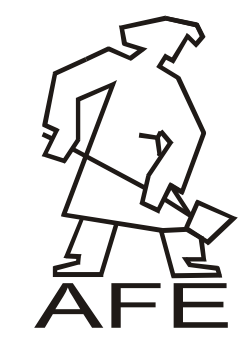

ARCHIVES

of

F OUNDRY ENG INEERING

DOI: $10.2478 / \mathrm{v} 10266-012-0030-0$

ISSN (2299-2944)

Volume 12

Issue $2 / 2012$

$25-28$

\title{
Modern Cored Wire Injection 2PE-9 Method in the Production of Ductile Iron
}

\author{
E. Guzik ${ }^{\mathrm{a} *}$, D. Wierzchowski ${ }^{\mathrm{b}}$ \\ ${ }^{a} A G H$ University of Science and Technology, Reymonta 23, 30-059 Kraków, Poland \\ ${ }^{b}$ Eisengießerei Monforts (actually EGM Automotive GmbH), Schwalmstr. 301, Mönchengladbach, Germany \\ *Corresponding author. E-mail address:guz@agh.edu.pl
}

Received 14-05-2012; accepted in revised form 31-05-2012

\begin{abstract}
The results of studies on the use of modern two cored wires injection method for production of nodular graphite cast iron with use of unique implementation of drum ladle as a treatment/ transport and casting ladle instead vertical treatment ladle was described. The injection of length of $\varnothing 9 \mathrm{~mm}$ wires, cored: in $\mathrm{FeSi}+\mathrm{Mg}$ nodulariser mixture and inoculant master alloy is a treatment method which can be used to produce iron melted in coreless induction furnace. This paper describes the results of using this method for possibility production of ductile iron under specific industrial conditions. In this case was taken ductile iron with material designation: EN-GJS-45010 Grade according PN-EN 1563:2000. Microstructure of 28 trials was controlled on internally used sample which has been correlated with standard sample before. The paper presents typical metallic matrix and graphite characteristic. Additionally, mechanical properties were checked in one experiment. Because of further possibility treatment temperature reduction only the rough magnesium recovery and cost of this new method are given.
\end{abstract}

Keywords: Drum Ladle, Cored Wire Injection Method, Ductile Iron, Fesi + Mg Nodulariser Mixture, Inoculant Master Alloy, Mechanical Properties, Magnesium Recovery, Vertical Ladle

\section{Introduction}

An important stage in the production of high- quality ductile cast iron was implementation into industrial practice new fully mechanised technique of introducing $\mathrm{Mg}$ - and inoculant reagents into molten alloy called cored wire injection method. This method was implemented for the first time in polish foundry in 1995 [1]. As a result of joint efforts of the Chair of Alloys and Composites Cast Engineering (at the Foundry Faculty at the University of Science and Technology in Cracow) with active participation of the Ferro-Term Łódź, this technique has been popularised over the past 17 years in a few domestic foundries [2]. For production of ductile iron in above mentioned foundries, technique of cored wire was used to treat the batches of molten alloy in ladles ranging in capacities from 0,15 up to $10 \mathrm{Mg}$. Cored wire injection method is applicable to both cupola- and electric melted iron furnace. Investigations of the cupola process carried out in two domestic foundries have fully proved that based on practical experience can be said that both the one- (Mg treatment) and two (with additional inoculant wire) cored wires method ensure low manufacturing costs and constant residual magnesium content at level of more $0,045 \mathrm{wt} . \%$, necessary to get nodular graphite. Setting of residual magnesium level in alloy is very easy; it is enough to change the length of feeding Mg- cored wire. This solution effectively eliminates time and labour of repeated preparation of individual batches of nodulariser and inoculant, typical in other methods.

Magnesium recovery and required length (weight of nodulariser) of wire injection to molten alloy are calculated from the following formula [1]: 
- magnesium recovery $\left(\eta_{\mathrm{Mg}}\right)$ is constant and characteristic for Mg-treatment method. It depends on several factors and may be calculated as:

$\eta_{\mathrm{Mg}}=\left[\left(0,76 \bullet \Delta \mathrm{S}+\mathrm{Mg}_{\mathrm{kr}}\right) \bullet \mathrm{m}_{\dot{\mathrm{z}}}\right] /\left(\mathrm{L} \bullet \mathrm{Mg}_{\mathrm{p}}\right), \%$

where:

0,76 - is the coefficient of sulphur and magnesium count., at.\%; $\Delta \mathrm{S}=\mathrm{S}_{1}-\mathrm{S}_{2}-$ is the difference between sulphur content in molten alloy before and after treatment, wt.\%;

$\mathrm{Mg}_{\mathrm{kr} .}$ - is the residual magnesium content, wt.\%;

$\mathrm{m}_{\dot{\mathrm{z}}}-$ is the molten alloy weight in ladle, $\mathrm{kg}$;

$\mathrm{L}-$ is the wire length, $\mathrm{m}$;

$\mathrm{Mg}_{\mathrm{p}}$ - is the magnesium content in 1metre of the cored wire,

$\mathrm{kg} / \mathrm{m}$;

- the following formula is used as a main tool for calculation of the wire length (weight of nodulariser):

$\mathrm{L}=\left[\left(0,76 \bullet \Delta \mathrm{S}+\mathrm{Mg}_{\mathrm{kr}}\right) \bullet \mathrm{m}_{\dot{\mathrm{z}}}\right] /\left(\eta_{\mathrm{Mg}} \bullet \mathrm{Mg}_{\mathrm{p}}\right), \mathrm{m}$

Another important aspect of magnesium- and inoculant treatment with cored wire injection method is its cost in comparison to other ones.

\section{Experimental procedure}

Although, since years is said in literature of the subject that ductile iron castings must be produced with use of vertical treatment ladle this experiment tried to proved that drum ladle can be taken for the same process of two cored wires injection method with same result as well. Common use of vertical treatment ladles comes from assumption which says that high of molten alloy column in ladle must be minimum $1.0:(1.5-2.0) \mathrm{x}$.

At the foundry of Eisengiesserei Monforts (actually EGM Automotive $\mathrm{GmbH}$ ) in Mönchengladbach-Germany, a special technique of $\mathrm{Mg}$ - and inoculation treatment was implemented. It was based on change of the ladle type and method of treatment. In case of the FeSiMg master alloy treatment at the bottom of the vertical treatment ladle was taken two $\varnothing 9 \mathrm{~mm}$ cored wires injection method in drum ladle that is use not only for treatment but also transport and pouring process. Additionally, the best angle of introducing the wires into molten alloy in drum ladle was chosen empirically (Fig. 1).

The charge mix (special pig iron + mild steel scrap + returns of nodular cast iron $=$ mean value of sulphur content equal 0,011 wt.\%) after melting and superheating in coreless induction furnace is set for tapping temperature. The drum ladle with capacity of about $0,95 \mathrm{Mg}$ is next filled with molten alloy and transported to the treatment chamber (Fig. 2). Weight of molten alloy in ladle is controlled and has range between 0,94 and 0,955 $\mathrm{Mg}$. After process the drum ladle is directly transported to the pouring line and used as casting ladle of green sand moulds.

The Mg- and inoculation treatment is carried out by means of two $\varnothing 9 \mathrm{~mm}$ wires injection method after parameter adjustment. Length of $\mathrm{FeSi}+\mathrm{Mg}$ filled cored wire is $50 \mathrm{mb}$. Magnesium content inside is $0,0315 \mathrm{~kg} / \mathrm{mb}$. Cored wire length used for inoculation process is $28 \mathrm{mb}$. Filling of both wires is presented on the Fig. 3.

For trials were taken two type of high-quality castings. Turbocharger housings with number of 16 molten alloy treatments and exhausting manifolds with number of 12 ones. Because of different wall thickness characteristics both groups have different treatment temperatures; respectively 1494 up to 1514 and 1470 up to $1486^{\circ} \mathrm{C}$. Residual magnesium level for turbocharger is 0,048 up to $0,06 \mathrm{wt} . \%$ and for manifolds 0,055 up to $0,064 \mathrm{wt} . \%$. This is correct due to different casting cooling rates and a little bit from shape of treatment ladle. Lower residual magnesium level is not able to ensure nodular cast iron in each section of casting that is ordered by automotive customers.

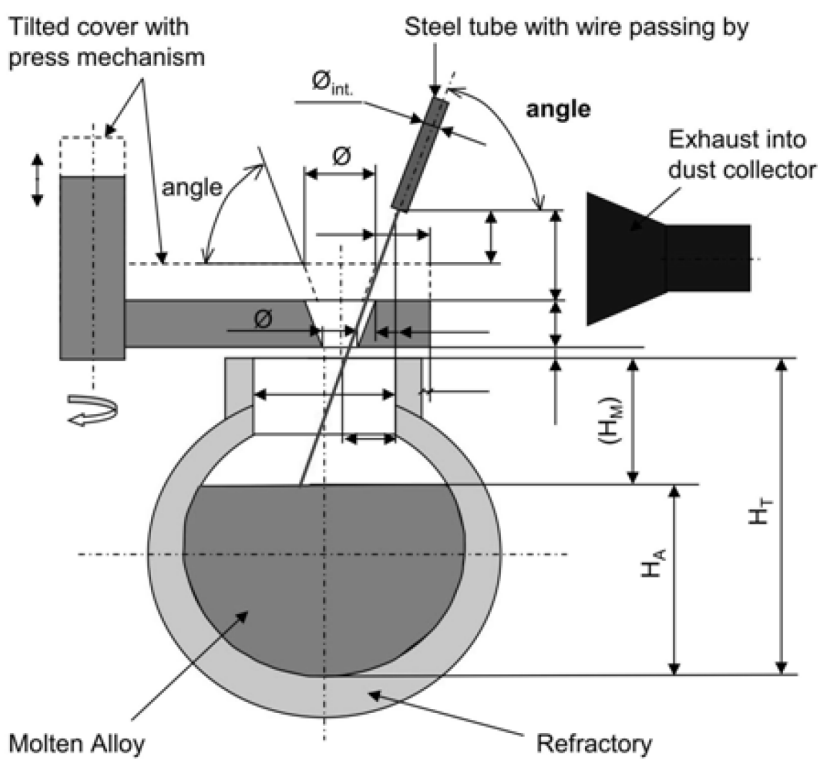

Fig. 1. Schematic view of placing the steel tube against molten alloy in drum ladle under treatment

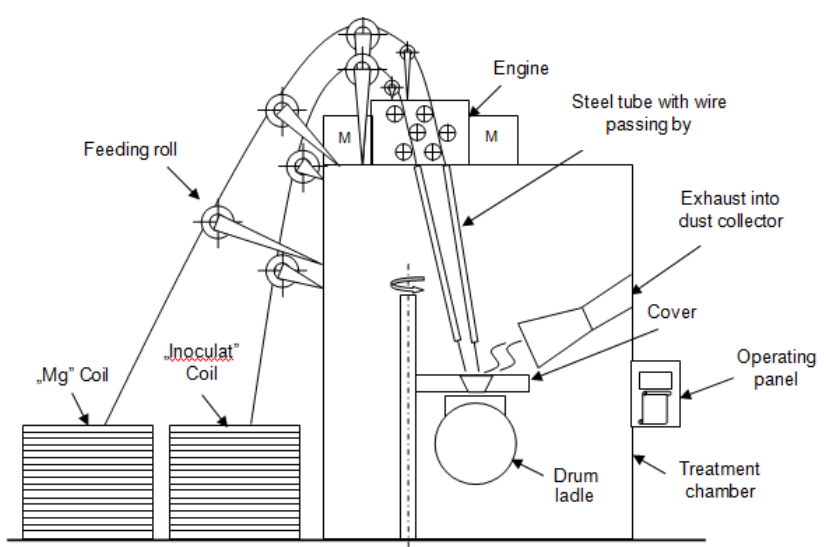

Fig. 2. Schematic view of the two cored wire injection method used during experiments 
a)

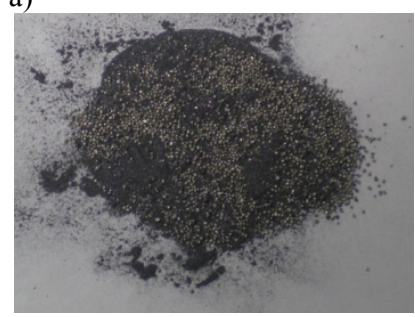

b)

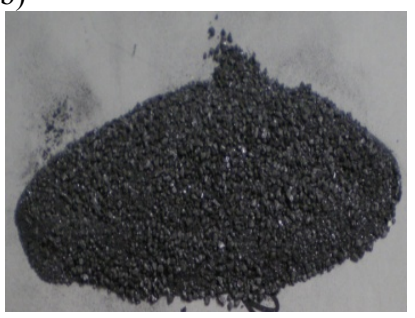

Fig. 3. Photographs of both cored wire fillings; FeSi $+\mathrm{Mg}$ nodulariser mixture a) and inoculant master alloy b)

Specimen for further microstructure analysis is casted with the last mould of all 28 trials and has been correlated with standard sample before. Controls of metallic matrix and graphite are made under the Nikon, Epiphot optical microscope.

One time together with experiment the standard sample was poured (type "YII" - $25 \mathrm{~mm}$ block standard). It was turned to the geometry of tensile test sample (shape C 14x70) according PN-EN 1563:2000. Mechanical properties were tested on the machine type UHP produce by LOS company. Hardness, HB $2,5 / 187,5$ is measured Dia Testor $3 \mathrm{~b}-\mathrm{E}$ device produce by Wolpert, Hahn \& Kolb.

\section{Results and analysis}

From analysis it follows that the range of parameters used in this method guarantees the microstructure and mechanical properties of tested nodular cast iron.

Metallographic examinations of all 28 specimens have proved that this technique produces ductile iron (material designation EN-GJS-450-10 Grade) with graphite type V, VI $>85 \%$ in regular shape of nodules and their size of 5 up to 6 according to EN-ISO 945. Metallic matrix is about $60 \%$ pearlite $+40 \%$ ferrite and free of carbides (Fig. 4).

The results of tensile test made from one experiment are in range of EN-GJS-450-10 standard PN-EN 1563:2000.

The mechanical properties UTS, YTS and A of ductile iron are shown in Table 1. a)

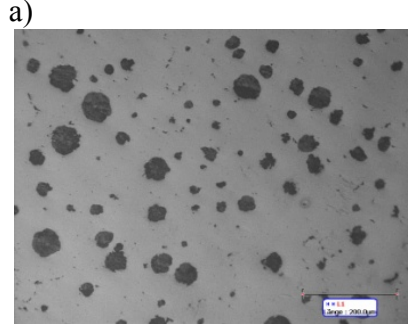

b)

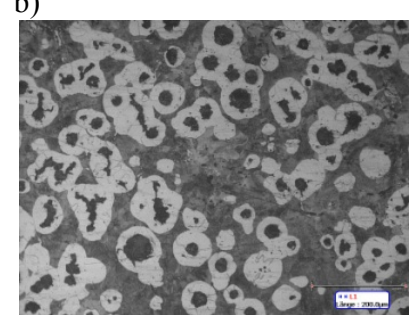

Fig. 4. The photomicrographs showing graphite after polishing a) and metallic matrix after etching, b) of ductile iron manufactured during experiments
Table 1.

Results of mechanical properties of ductile iron in "YII" block standard

\begin{tabular}{cccc}
\hline Properties & UTS, MPa & A, $\%$ & YTS, MPa \\
\hline Standard, min. & 450 & 10 & 310 \\
\hline Results of trials & 512 & 11 & 356 \\
\hline
\end{tabular}

Hardness HB2,5/ 187,5 measured with his one trial is equal 204.

Analysis of scrap rate of castings made during experiments shows decreasing in compare to old technique of nodular cast iron (DI) manufacturing. Mean value of magnesium recovery $\left(\eta_{\mathrm{Mg}}\right)$ was calculated with use of formula (1). On the schematic diagram all parameters value are shown (Table 2 ). Recovery value as well as magnesium residual content for turbochargers is lower because of higher $\mathrm{Mg}$ - and inoculation treatment temperature of molten alloy (Fig. 5).

Table 2.

Parameters of cored wires injection method for production of nodular graphite cast iron

\begin{tabular}{lcc}
\hline \multirow{2}{*}{$\begin{array}{l}\text { Parameter mean } \\
\text { values: }\end{array}$} & \multicolumn{2}{c}{ Type of casting } \\
\cline { 2 - 3 }$\Delta \mathrm{S}$ & \multicolumn{2}{c}{0,004} \\
\hline $\mathrm{Mg}_{\mathrm{kr}}$ & 0,056 & Manifolds \\
\hline $\mathrm{m}_{\dot{\mathrm{z}}}$ & 946 & 0,060 \\
\hline $\mathrm{L}$ & 50,6 & 942 \\
\hline $\mathrm{Mg}_{\mathrm{p}}(\operatorname{0,0317}$ & 50,2 \\
\hline$\eta_{\mathrm{Mg}}(\min , \max )$ & $34,5(30$ up to 38$)$ & $37,7(35$ up to 41$)$ \\
\hline
\end{tabular}

The cost analysis was made for the process of molten alloy $\mathrm{Mg}$ - and inoculation treatment carried out with two cored wires injections method as well. The following calculations were made:

- Mg-treatment with cored wire (properties: wire weight $=0,225$ $\mathrm{kg} / \mathrm{mb}$; price per $1 \mathrm{~kg}$ of wire $=2,35$ EUR weight of molten alloy in ladle $=944 \mathrm{~kg}$; length of wire $=50 \mathrm{mb}$ ) hence $50 \mathrm{mb}$. $0,225 \mathrm{~kg} / \mathrm{mb}=11,25 \mathrm{~kg} \bullet 2,35 \mathrm{EUR} / \mathrm{kg}=26,44 \mathrm{EUR}$, length of $\mathrm{Mg}=28,01$ EUR.

- Inocuation treatment with cored wire(properties: wire weight = $0,240 \mathrm{~kg} / \mathrm{mb}$; price per $1 \mathrm{~kg}$ of wire $=2,27$ EUR length of wire $=28 \mathrm{mb}$ ) hence $28 \mathrm{mb} \bullet 0,240 \mathrm{~kg} / \mathrm{mb}=6,72 \mathrm{~kg} \bullet 2,27 \mathrm{EUR} / \mathrm{kg}=$ 15,25 EUR, length of inoculation $=16,16$ EUR.

The final cost of length $\mathrm{Mg}$ alloy $\mathrm{Mg}$ wire- and inoculation wire treatment is 44,17 EUR.

Reducing the temperatures of pouring let reduce temperatures of molten alloy treatment and that enables length of Mg-treatment wire to be reduced, so that magnesium recovery increases and the final cost decreases. Results of experiments have indicated that residual magnesium content basing on the initial sulfur content and weight- as well temperature of treated molten alloy in the ladle. Comparing with old technique has been used in the foundry before, the new way of $\mathrm{Mg}$ - and inoculation treatment with two cored wires being convoyed into drum ladle offers the following advantages it:

a) ensures process stability and quality;

b) ensures safe work conditions in a foundry (no dust and no alloy "splashes" from the treatment ladle); 
a)

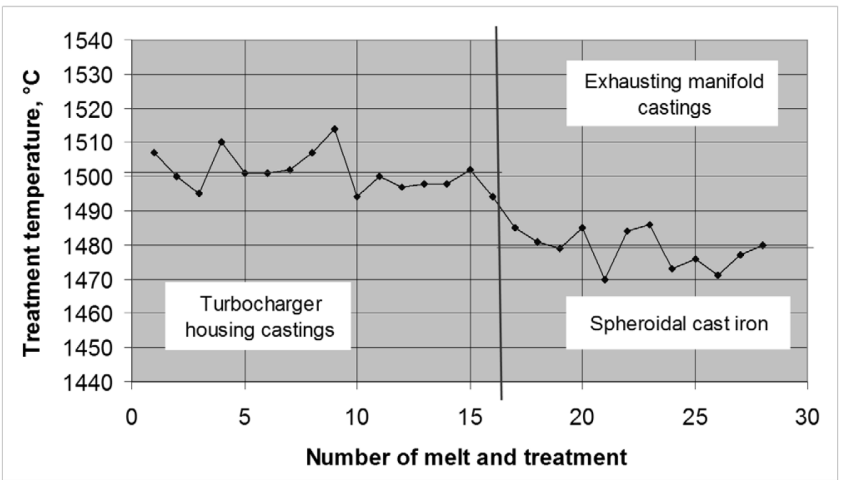

b)

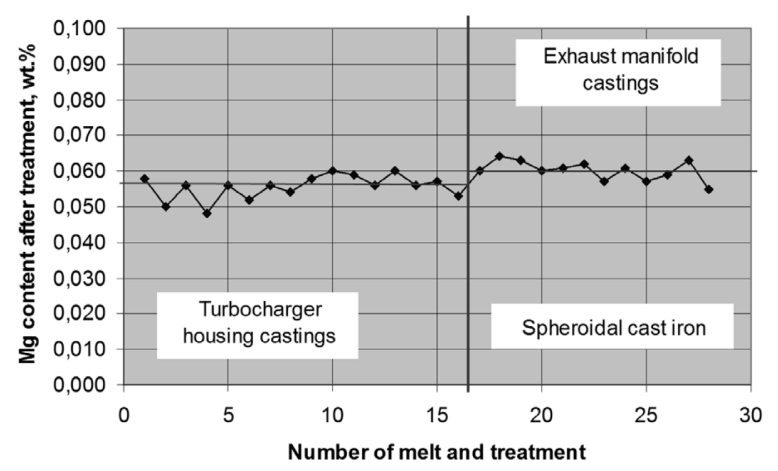

Fig. 5. The change of treatment temperature a) and residual magnesium content $b$ ) in nodular cast iron curried out with two Ø $9 \mathrm{~mm}$ cored wires injection method in drum ladle

c) insures process flexibility under variable initial parameters, like sulphur content in molten alloy, as well as temperature and weight of molten alloy;

d) enables collecting and storing the data in computer of control device;

e) reduce about 50 grades temperature loss because of using only one ladle in whole production process of nodular graphite iron (Fig. 6);

f) ensure pouring of thin wall sections in exhausting manifolds or turbocharger housings;

g) reduce production cost (because of less number of ladles in process, energy saving, reduction of refractory consumption and labour demand;

h) increase process efficiency.

\section{Conclusions}

Based on conducted studies of nodular cast iron production with new technique of $\mathrm{Mg}$ - and inoculation treatment of molten alloy in the drum ladle following conclusion have been generated:

1. Experiment of profitable use of the drum ladle as a treatment ladle was finished successfully.
2. Results of nodular cast iron production proved that this method has gained full approval of the foundry industry.

3. This is important stage opening without any doubts possibility of high-quality castings manufacturing with use of $\mathrm{Mg}$ - and inoculation treatment of molten alloy in the drum treatment ladle.

4. One ladle in process (as treatment/ transport and pouring ladle) saving 50 grades of temperature loss, that gives foundries big advantage due to of elimination of molten alloy transferring form the vertical treatment ladle to the pouring one.

5. The whole nodular cast iron production process is effective.

6. Magnesium recovery could be increased and cost decreased in case of optimization of treatment temperature that means temperature reduction.

7. High of the molten alloy column in ladle has not so big influence on magnesium recovery in compare mainly to weight of batch, treatment temperature and base sulfur content in base molten alloy.

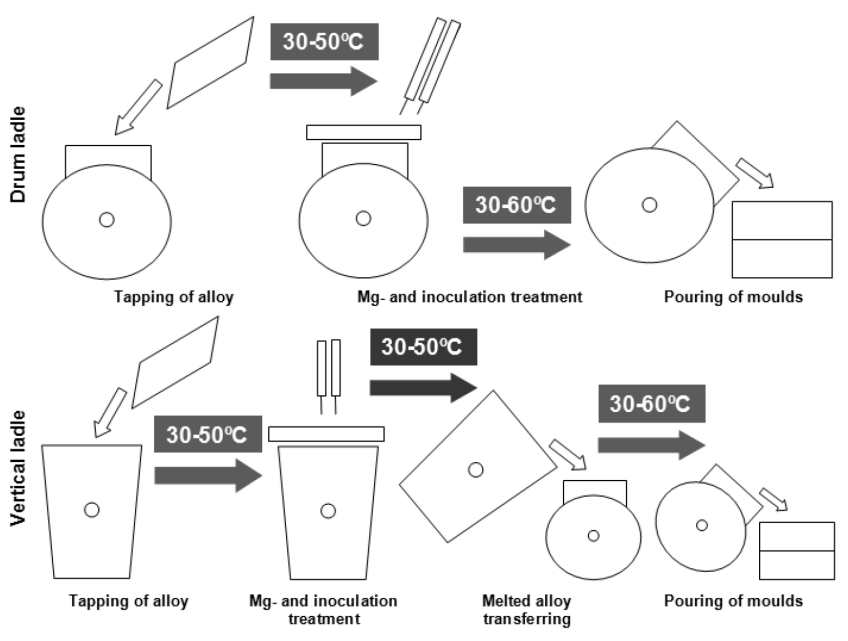

Fig. 6. Comparing with old technique has been used in the foundry before, the new way of $\mathrm{Mg}$ - and inoculation treatment with two cored wires being convoyed into drum ladle

\section{References}

[1] Guzik E. (2001). Some selected problems concerning the processes of cast iron improvement. Archives of Foundry Engineering. Polish Academy of Sciences - Katowice, Monograph, No. 1M, 1-128.

[2] Guzik E., Asłanowicz M., Kluk R. (1995). Using cored wire in the production of nodular cast iron. Solidification of Metals and Alloys. 22, 76-81. 